\title{
Liquidity of Tunisian Stock Market: A Panel Var Estimation
}

\author{
Wafa Chabeb ${ }^{1} \&$ Adel Boubaker ${ }^{2}$ \\ ${ }^{1}$ Accounting and Finance Department, ISCAE, University Manouba, Tunisia \\ ${ }^{2}$ Faculté des Sciences Economiques et de Gestion de Tunis, University Tunis ELManar, Tunisia \\ Correspondence: Wafa Chabeb, Accounting and Finance Department, ISCAE, University Manouba, Tunisia.
}

Received: August 7, 2021

Accepted: August 19, 2021

Online Published: August 23, 2021

doi:10.5430/afr.v10n3p93

URL: https://doi.org/10.5430/afr.v10n3p93

\begin{abstract}
The purpose of this paper is to estimate the functions impulsions-response of liquidity on the Tunisian Stock Exchange (TSE). We will use the methodology proposed by Abrigo and Love (2016). Our study is done on an order-driven market. The data is composed of high frequency data of orders listed on the TSE for the period April 2014 to June 2014. Inspired of the study of Jarnecic and Snape (2014), we apply a panel VAR model to stocks traded in continuous in order to examine the dynamic interactions between spread, volatility, size and frequency of transactions. Then we study the liquidity of the TSE through the impulse response function of the Panel VAR model. Our findings show dynamic relationships between spread, volatility, size and frequency of trading. Some differences exist in the dynamics of liquidity when we take into account the trading intensity of the stock. Furthermore, we note that shocks are absorbed after three gaps of 45 minutes.
\end{abstract}

Keywords: transactions frequency, market liquidity, volatility, order driven market, panel VAR

\section{Introduction}

Estimation of market quality is an important topic for empirical analysis of market efficiency and microstructure. Market quality is estimated with the order submission strategies of participants, the nature of liquidity and volatility. The arrival of high-frequency participants, who have the ability to submit, amend and cancel orders faster than most other participants could challenge the current understanding of orderbook dynamics and liquidity provision, as suggested by Hasbrouck and Saar (2009). Prior studies examine limit order book dynamics and have provided researchers and practitioners with a number of stylized empirical observations of the limit order book. Despite this important role, their estimates are not available, or where available, are subject to error.

The valuation of spread requires an intraday dataset including the volume and the better prices quoted. In the spirit of Hautsch and Huang, 2012, we advise a high frequency vector autoregression (VAR) on Panel data referring to the work of Abrigo and Love, 2016. Our objective will be to capture the dynamics of short-term liquidity, price volatility, the pricing process and their relationship to order frequency. The model shall incorporate relevant characteristics of the process of entry of orders with a limited price on the market, including the variables representing the dimensions of the order book defined by the frequency of placing orders. Liquidity is quantified by the effective spread static component of liquidity. Our approach offers a number of methodological advantages over the few studies examining other components of liquidity. Indeed, most studies have looked at resilience in similar settings. Infact, impulse response functions have been widely discussed in previous studies on resilience such as Hmaied and al., 2006 and Coppejans and al., 2004.

Hmaied et al. (2006) study the liquidity dynamics of the Tunisian equity market through a model incorporating market depth, resilience and volatility. They find significant interactions between these variables and their analysis of the impulse response function revealing that liquidity shocks are absorbed more rapidly by frequently traded equities. Coppejans et al. (2004) analyzed liquidity dynamics in the order book on the Swedish index futures market and found that increases in market liquidity, as measured by the depth of the order book, have a positive effect that reduces volatility. Danielsson and Payne (2002) adopted a VAR model to jointly estimate the dynamic effects of the spread, depth, volume and volatility of the DEM/USD exchange spread traded on the Reuters D2000-2 FX electronic system. Focusing on determining the depth of the order books, they find that volatility increases and the spread are wider as a result, leading market participants to provide less short-term liquidity. Their work shows that the effect of 
transaction volume on depth depends on the direction of the purchase or sale negotiation. Indeed, after a buying activity on the market, the depth of the buying side increases while the depth of the selling side decreases. Empirical studies have also adopted other approaches to examine market liquidity. Degryse et al. (2005) used an event study approach, analyzing the liquidity of the Paris Stock Exchange by observing the behavior of variables such as the spread, the depth and duration of execution of orders at the best limits during an aggressive order submission interval. Large (2007) proposed a multivariate model to quantify the liquidity of the London Stock Exchange through a study of events. Dong et al. (2007) examined liquidity using the Kalman-filter estimation methodology. Using NYSE data, their study makes a number of important findings with a focus on how certain factors affect liquidity. The authors note that price, trade size and equity volatility are negatively linked to market liquidity while trading activity has a positive relationship. However, Dong et al. (2007) only considers liquidity supported by designated market makers.

The aim of this paper will be to understand the importance of the strategies adopted by traders in Tunisian Stock exchange in terms of improving the quality of the market. The main measures of the quality of the financial markets were used to better detect the contribution of strategies and the role played by traders in the liquidity contribution of the market, the volatility of the carnet and the price formation process. We will estimate them at an intraday horizon on an emerging market. The scarcity of the data on which we work also gives importance to our academic work as well as the estimation method which, to our knowledge, has not been used in a context like ours. The dynamic of liquidity in the Tunisian Stock Exchange (TSE) measured by the spread, the volatility and size by using the Panel VAR methodology will inform about the response of these variables to the choc of order strategy adopted by Tunisian traders in the TSE.

The remaining of this paper is organized as follows. The first section presents the literature review. The second develop the structure of the Tunisian Stock Exchange and dataset. The methodology used is then discussed in the third section. Results are then presented and debated, and the paper ends with a concluding section.

\section{Literature Review}

The order submission strategies and the dynamics of securities prices has drawn the attention of practitioners and academicians for the complex relationship that exists between the nature of liquidity, the cost of trading and the information circulated in the market.

In the finance literature, many studies illustrate the impact of high frequency trading on market quality. Using data from trading algorithms, Hendershott and Riordan (2011) confirm that algorithm's traders orders submitted improves liquidity. Kelejian and Mukerji (2016) using data before the advent of algorithm trading to closely time (1985-2012) show that the orders from AT move the market away from fundamentals.

The arrival of high frequency traders who have the facility to submit, amend and cancel orders at high frequency speed could contest the explanation of liquidity provisions of order book as advised by Hasbrouck and Saar (2009). Jarnecic and Snape (2014) explore the submission of liquidity by participants in the security market in presence of HFT. An increase of orders cancellations, small trade sizes and the complexity of trading had a direct effect on the bid-ask spread (measure of liquidity of the market), volatility of the order book and price pressure.

Examining the causal relationship between order submission strategy, liquidity of the order book, volatility and market capitalization using an integrated approach could address various apprehensions about the orders submission strategies, and assist practitioners who are looking to execute orders in this environment.

Prior studies, Ahn, Bae and Chan (2001), Biais, Hillion and Spatt (1995), Handa, Schwartz and Tiwari (2003), Hollifield, Miller and Sandas (2004), Griffiths, Smith, Turnbull and White (2000), and Ranaldo (2004) focus on limit order books containing public supply of liquidity. They examine limit order book dynamics and have provided researchers and practitioners with a number of formalized empirical observations of the limit order book. In a recent study Jarnecic and Snape (2014) examined HFT on the London Stock Exchange. They analyzed the orders strategies submission and their contribution to liquidity provision. Given their advantage in speed, the HFT alter the properties of the limit order book. They reduce temporal imbalances in orders submissions and translate their strategies into liquidity provisions for large, medium and small stocks. Our findings in the TSE is stronger for small stocks.

Faucault and Menkveld (2008) is the most study that confirms that the trading system impacts the market quality and especially liquidity.

Our paper's contribution is the estimation of a model that treated the HFT strategies and their impact on market quality in an emerging market based on human trading. Also we want to estimate variables that measure the frequency of trading transactions, liquidity, volatility and securities capitalizations. 
The main hypothesis of our study is given as:

Research hypothesis: The frequency of ordering improves the quality of orders driven markets. Two sub-hypotheses will be tested through the five regressions:

H1: A shock in the frequency of placing orders has a one-time impact on the size of the effective spread, volatility, the price of securities and market capitalization.

H2: The size of the effective spread, volatility, and market capitalization have a delayed impact on the frequency of placing orders.

\section{Structure of the TSE and Dataset}

This section presents the structure of the Tunisian Stock Exchange, the data used and the model estimated in this study.

\subsection{Description of the TSE}

The Tunisian Stock Exchange is a pure order-driven market where investors can choose between market and limit orders. Liquidity is only provided by limit order traders. Trading is carried out from 9.00 a.m. to 02.00 p.m. from Monday to Friday. It starts by a pre-opening session (from 9:00 am to 10:00 am). The TSE applies two trading methods: call auction and continuous trading. The market opens by a call auction for all stocks at some point of time during the first five minutes opening period. For liquid stocks, this is followed by a continuous market until 02:00 p.m. Limit orders require a price either above the current ask or below the current bid and offer price improvement relative to market orders who don't have limit on prices and aspects for immediate execution. A market order is immediately executed however a limit order faces the risk of non-execution. In fact, limit orders are executed according to order price and time of submission based on priority. First, orders are matched in the order in which they are entered into the system, based on the best price: the higher bid for the buy side and the lower ask for the sell side. The system applies, indeed, a time priority: at the same price, the order first entered into the system must be fully executed before any order placed later.

\subsection{Dataset}

The data supplied includes time-sequenced messages that completely describe all trades and order book activity for our sample period from April 1, 2014, to June 30, 2014. we collected the orders placed from the central order book of our stock market. For each security, buy and sale orders with limited prices are recorded every 45 minutes. It should be noted that the sample consisting of 40 securities in order to satisfy the cylinder panel condition. This approach is essential for the application of the VAR panel. The nature of the traders, the topology of the orders placed and allowed us to define their strategies

The model we will be testing will be inspired by the one developed in the studies of Jarnecic and Snape (2014) which complements those of Hasbrouck and Saar (2013).

Jarnecic and Snape (2014) estimate the following system of simultaneous equations using data from the five-minute intervals

$$
\begin{array}{r}
\text { HFT }_{i, j}=a_{1}+a_{2} \text { Liq }_{i, j}+a_{3} I_{j}+a_{4} \text { Volatility }_{i, j}+a_{5} \text { Size }_{i, j}+\varepsilon_{1} \\
\text { Liq }_{i, j}=\beta_{1}+\beta_{2} \text { HFT }_{i, j}+\beta_{3} I_{j}+\beta_{4} \text { Volatility }_{i, j}+\beta_{5} \text { Size }_{i, j}+\beta_{6} \text { InvPrice }_{i, j}+\varepsilon_{2}
\end{array}
$$

The first equation determines the participation of HFT firms as a function of either the bid-ask spread or quoted depth, stock price volatility and stock size, as well as market-wide HFT.

The second equation determines the bid-ask spread or quoted depth as a function of HFT activity, stock price volatility, stock size and stock price, as well as a market wide liquidity measure. The coefficients that estimate interest are:

- The effect of liquidity on the HFT activity, $\alpha 2$

- $\quad$ The effect of HFT activity on the liquidity measure, $\beta 2$.

In addition to that, we define the following parameters:

- $\quad H F T i, j$ is the high-frequency participation rate 
- Liqi,j is the percentage quoted bid-ask spread

- Volatilityi,j is the log of the high divided by low mid-quote price for the period

- Sizei,j is the log of market capitalization

- InvPricei,j is the inverse of the stock price.

In the spirit of Foucault, Roell and Sandas (2003) and Hasbrouck and Saar (2013), Jarnecic and Snape (2014) adopt a variation of the simultaneous equations' framework.

Moreover, in our topic we implement a panel VAR estimation as developed by Abrigo and Love (2015) which will be detailed in the next session.

\section{Methodology}

Time-series vector autoregression (VAR) models originated in the macro econometrics literature as an alternative to multivariate simultaneous equation models (Sims, 1980). All variables in a VAR system are typically salted as endogenous, although identifying restrictions based on theoretical models or on statistical procedures may be imposed to disentangle the impact of exogenous shocks onto the system.

With the introduction of VAR in panel data settings (Holtz-Eakin, Newey and Rosen, 1988), panel VAR models have been used in multiple applications across fields.

\subsection{Variables Measures}

TPI : Trader Position Index : we create a variable appropriate to our context knowing that we keep the same method of estimating this variable. We are looking to estimate the order placement rate by traders on TSE for the 40 securities most present on the order book in terms of the number of buy and sell orders executed over intervals of 45 minutes.

1- $T P I=\frac{\text { Number of orders executed for each security } y_{i, 45 m n}}{\text { Number of orders executed for each security throughout the day }}$

$2-\boldsymbol{L} \boldsymbol{i} \boldsymbol{q}_{i, j}=$ the percentage quoted bid-ask spread $=\frac{\mathbf{A}_{\mathbf{t}}-\mathbf{B}_{\mathbf{t}}}{\mathbf{P}_{\mathbf{t}}-\mathbf{Q}_{\mathbf{t}}}$

The spread is measured at the first best limit at 45 -minute intervals.

The choice of the effective spread is justified by the fact that the Bid and the Ask displayed in the book do not always coincide with the price of the transaction carried out. Studies by Huang and Stoll (1997) on transaction costs on NYSE and NASDAQ show that the effective spread does not measure the difference between Bid and Ask but also the difference between the transaction price and the middle of the spread. This measure can be a better indicator than the displayed range.

3- Size $_{i, j}=$ Log of market capitalization.

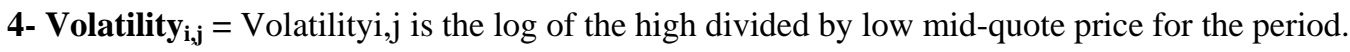

\subsection{Regression Model}

The VAR Panel of the endogenous variables of the model is defined by the following writing.

Four equations will be estimated through the Panel VAR

$$
\begin{aligned}
& \operatorname{TPI}_{i, t}=\boldsymbol{T P I}_{i, t-1} A_{1}+\boldsymbol{T P I}_{i, t-2} A_{2}+\cdots+\boldsymbol{T P I}_{i, t-p} A_{p}+e_{i, t} \\
& \text { Spread }_{i, t}=\text { Spread }_{i, t-1} A_{1}+\text { Spread }_{i, t-2} A_{2}+\cdots+\text { Spread }_{i, t-p} A_{p}+e_{i, t} \\
& \text { Volatility }_{i, t}=\text { Volatility }_{i, t-1} A_{1}+\text { Volatility }_{i, t-2} A_{2}+\cdots+\text { Volatility }_{i, t-p} A_{p}+e_{i, t} \\
& \text { Size }_{i, t}=\text { Size }_{i, t-1} A_{1}+\text { Size }_{i, t-2} A_{2}+\cdots+\text { Size }_{i, t-p} A_{p}+e_{i, t} \\
& i \in\{1,2, \ldots, N\}, \quad t \in\{1,2,3, \ldots, T\}
\end{aligned}
$$

We estimate our model by also using the Generalized Moment Method (GMM). The important individual dimension selected and the control of the heterogeneity of the sample are the reasons why we chose the individual effect model. In this study, panel vector autoregression (PVAR) methodology was adopted. The PVAR combines the traditional VAR approach, which treats all the variables in the system as endogenous, with the panel data approach, which 
allows for unobserved individual heterogeneity (Love and Zicchino, 2006). The empirical model for trading frequency (TPI), liquidity (Spread), volatility (volatility) and firm size (size) were given in the system below. The optimal lag given by the criteria of Andrews and Lu (2001) was based on the first-order PVAR.

\section{Empirical Results and Discussions}

This section reports the empirical results from the system-generalized method of moment PVAR and the impulse response functions analysis.

\subsection{System-GMM PVAR Causality Results}

Three steps must be validated before the PVAR estimate: the stationarity of variables; The stability of the model and the optimal lag of the model. The descriptive statistics of the data raised from the Tunisian stock exchange are summarized in table1.

Table 1. Descriptive Statistics

\begin{tabular}{llllllll}
\hline & Obs & Mean & Std Dev & Min & Max & Skewness & Kurtosis \\
\hline TPI & 15252 & 0.144 & 0.126 & 0 & 0.75 & 0.799 & 3.515 \\
Spread & 15252 & 0.127 & 0.737 & -16.56 & 13.99 & 6.502 & 126.504 \\
Volatility & 15252 & 0.132 & 0.198 & 0 & 7.488 & 8.801 & 244.338 \\
Size & 15252 & 6.241 & 5.402 & 0 & 21.983 & -0.066 & 1.405 \\
\hline
\end{tabular}

The stationarity condition is checked, we can estimate our Panel VAR and essentially highlight the response functions of each variable to a shock of the variable explaining the positions taken by traders on the Tunisian stock exchange, namely TPI.

Table 2. Unit Root Test

Fisher-type unit-root test for TPI, Spread, Volatility, Size

Based on augmented Dickey-Fuller tests

Ho: All panels contain unit roots $\quad$ Number of panels $=\quad 41$

Ha: At least one panel is stationary $\quad$ Number of periods $=\quad 372$

\begin{tabular}{lll}
\hline & Statistic & p-value \\
\hline TPI & 2955.5796 & $0.0000^{*}$ \\
Spread & 2920.1078 & $0.0000^{*}$ \\
Volatility & 2955.5796 & $0.0000^{*}$ \\
Size & 2498.3171 & $0.0000^{*}$
\end{tabular}

Table 3 presents the results of the estimate related to the impact of the TPI on the different variables introduced into the matrix. The results of the Panel Var estimates allow us to explain the links between the market liquidity defined by the effective spread, the strategies adopted by the traders, the volatility and the size.

We begin our analysis with the first regression of the Var Panel linking the order execution frequency (TPI) to the other measures. The results allow us to announce the following conclusions. 
Table 3. Estimated causality results from the dynamic panel SYS-GMM

\begin{tabular}{lllll}
\hline \multirow{2}{*}{ Independents Variables } & TPI & Spread & Volatility & Size \\
\hline TPI & $12,16 \%$ & $33,39 \%$ & $10,27 \%$ & $-95,78 \%$ \\
L1. & $(0.000)^{* * *}$ & $(0.000)^{* * *}$ & $(0.000)^{* * *}$ & $(0.015)^{* *}$ \\
Spread & $0,37 \%$ & $10,43 \%$ & $-2,85 \%$ & $-0,61 \%$ \\
L1 & $(0.067)^{*}$ & $(0.008)^{* *}$ & $(0.432)$ & $(0.920)$ \\
Volatility & $2.02 \%$ & $3,74 \%$ & $7,60 \%$ & $77,90 \%$ \\
L 1 & $(0.002)^{* *}$ & $(0.272)$ & $(0.000)^{* * *}$ & $(0.015)^{*}$ \\
Size & $-0,006 \%$ & $-0,08 \%$ & $0,04 \%$ & $56,69 \%$ \\
L1 & $(0.014)^{* *}$ & $(0.000)^{* * *}$ & $(0.346)$ & $(0.000)^{* * *}$ \\
\end{tabular}

Heteroskedasticity robust standard errors in parenthesis. $* \mathrm{p}<0.1 . * * \mathrm{p}<0.05 . * * * \mathrm{p}<0.01$.

The five variables have an impact on the positions taken by the traders, indeed, all the coefficients are significant and the sign expected in the first equation relative to TPI at lag order (1). Traders indeed, adjust their positions by referring to previous positions. The positive sign coefficients are relative to TPI, Spread and Size; the volatility had a negative sign which is also consistent with the preference of traders to contexts of stability and not high price volatility. A result specific to our market.

The second regression explaining liquidity by transaction intensity, volatility, the inverse of price, and capitalization gives the following results:

All variables except volatility give significant coefficients. The most important coefficient is assigned to the variable TPI with a percentage of $33.39 \%$ significant to $1 \%$. This corroborates the results found by Hasbrouck and Saar (2013) and Jarnecic and Snape (2014). A second finding relates to the correlation between the lag of the effective spread and its present value. With a positive coefficient of $10.43 \%$ and a significance of 5\%; traders take into account in this sense the spread already quoted in fixing the prices of their orders. Finally, we noticed a negative and non-significant correlation between market liquidity and stock volatility mainly due to the behavior of our traders who avoid actively participating or providing liquidity to the market during periods of high volatility which thwarts the results of Jarnecic and Snape (2014) who find that HF Traders, in times of high volatility and uncertainty, are more active in the market in order to take advantage of any price changes and adjust their positions accordingly.

The third volatility regression allows us to draw the following conclusions:

The trading frequency and spread positively influence the volatility of securities. Indeed, wider spreads encourage traders to place increasingly aggressive orders on the market. The same remark for the transaction frequency, the more it increases, the more the prices of the securities change and adapt to the demand of the stakeholders which impacts the volatility of the securities. Note that volatility influences the seller side of the book rather than the buyer as confirmed in the study of Zhang (2010). Hmaid et al (2006) in their work on the Tunis place relating depth on both sides of the market to the volatility of securities confirm this observation.

The intensity of transactions negatively impacts the capitalization of securities. Among the factors that make it possible to measure the difficulty of trading an asset is its trading volume.

Since the studies of Harris (1994), Stange and Kaserer (2011), Rosch and Kaserer (2013), capitalization is assumed to correlate positively with order flows, negatively with the spread. This is confirmed by our findings in the context we are studying. So the negative sign found between market capitalization and market liquidity is expected. Market capitalization reflects the size of the company. Several studies such as Harris (1994), Stoll (2000) Hasbrouck and Saar (2013) consider the size of the company as a proxy for the level of public information. In addition, the larger the size of the firm, the smaller the information asymmetry and the bid-ask spread is narrow. We complete our study with a Granger causality test and an interpretation of the graphs of the response functions of each variable in the matrix. 
The Granger causality tests we conducted on the matrix of endogenous variables yielded results that show a spread-transaction strategy causality relationship (TPI spread). In addition, we focused on the factors that cause spread variation as a measure of liquidity and an indicator of the quality of the financial market. The matrix variables have an impact in the sense of Granger on the liquidity of the market is a condition verified with a prob chi2 of 0.000 . A long-term causality except that in our case the nature of the intraday data allows us to confirm the existence of causality during a day and therefore for the 5 intervals of $45 \mathrm{mn}$ composing our day of quotation as well as on the long term that is the estimation period with 62 trading days from April 01 to June 30, 2014. Our results are similar to those of Hasbrouk and Saar (2013) linking the intensity of transactions to the quality of the market. Their studies show that the intensity of transactions has a long-term impact on the quality and essentially liquidity of the financial market. Table 4 allows us to detect the degree of causality and whether or not it exists and in what sense for the four variables estimated through the Panel Var model.

Table 4. Panel Granger causality results

\begin{tabular}{lllll}
\hline \multicolumn{4}{l}{ Independents variables } & \\
\hline Equation & TPI & Spread & Volatility & Size \\
TPI & - & 3.950 & 9.470 & 6.006 \\
& & $(0.067)$ & $(0.002)$ & $(0.014)$ \\
Spread & 20.297 & - & 1.209 & 26.723 \\
& $(0.000)$ & & $(0.272)$ & $(0.000)$ \\
Volatility & 32.767 & 0.618 & - & 0.887 \\
& $(0.000)$ & $(0.432)$ & & $(0.346)$ \\
Size & 5.931 & 0.010 & 5.901 & - \\
& $(0.015)$ & $(0.920)$ & $(0.015)$ & \\
\hline
\end{tabular}

Probability values are in parenthesis.

$* \mathrm{p}<0.1$.

$* * \mathrm{p}<0.05$.

$* * * \mathrm{p}<0.01$.

\subsection{Impulse Response Analysis}

This section presents the impulse response functions and the 95\%confidence interval band that was generated based on 200 MonteCarlo simulations. The orthogonalization of the VAR residuals helps to isolate the response of effective spread, volatility and size to a shock on TPI. Fig .1 reports the global Impulse Response Function of spread, volatility and size to a shock in traders orders strategies. The same figure also shows the dynamic responses of the various variables: transaction frequency, spread, price volatility and market capitalization, to the shocks of each one which allow us to draw the following conclusions. 

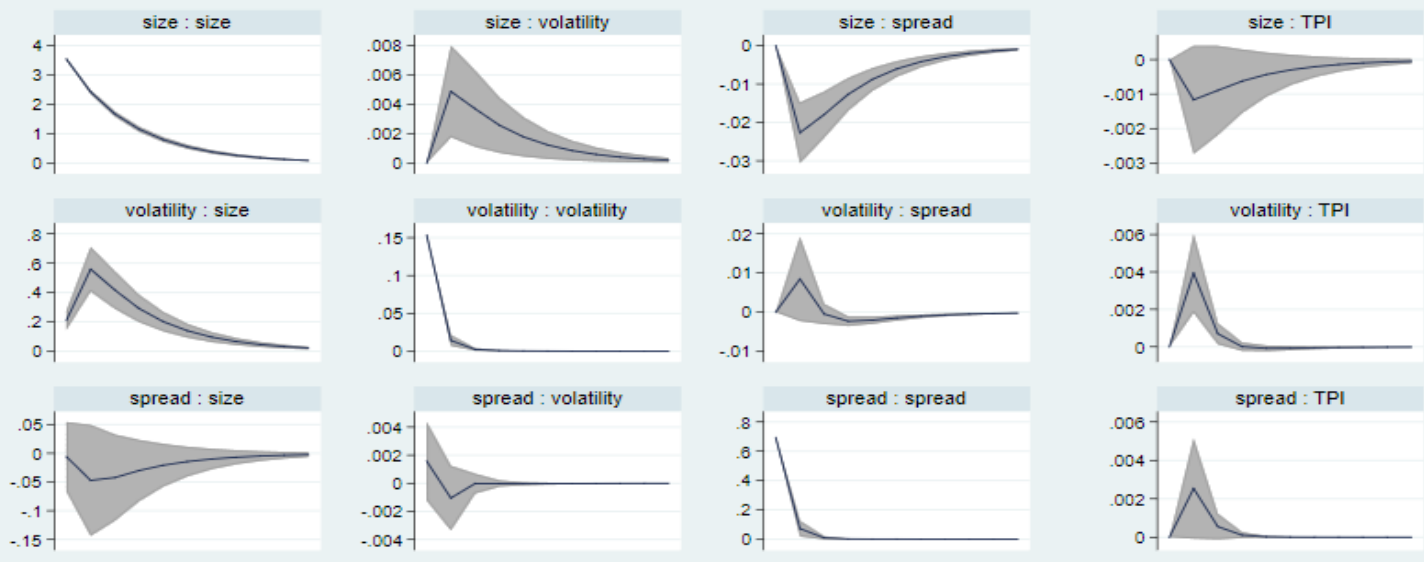

spread : TPI

TPI : size

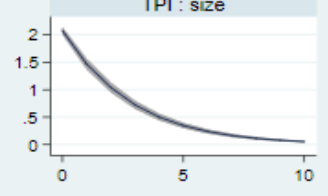

TPI : volatility

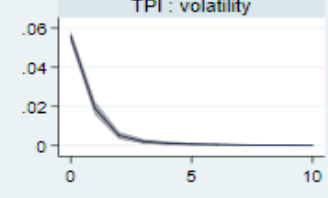

TPI : spread
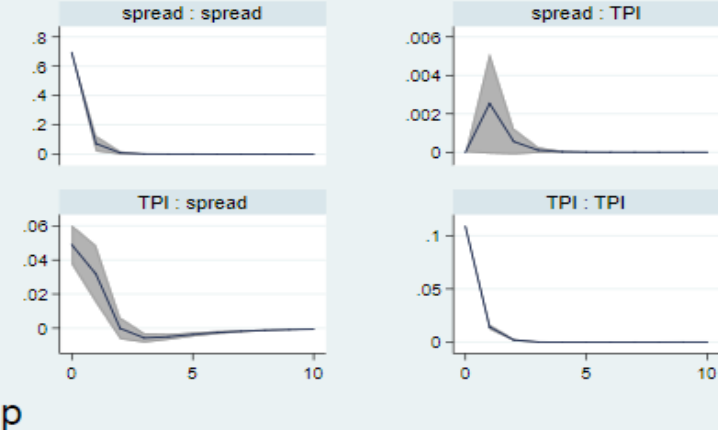

TPI : TPI

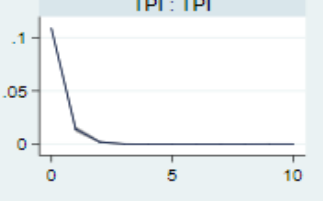

step

$95 \% \mathrm{Cl}$ Orthogonalized IRF

impulse : response

Figure 1. Impulse-response functions

A drop in demand on securities for the interval immediately following the opening of the quotation session (the first 45 minutes of the session) assiduously from a small fall until the 3rd interval to finish the session in a position of stagnation and equilibrium. Indeed, the fall is explained by the asymmetry of information conveyed by the arrival on the market of a significant flow of order (Stoll (2000), Kaserer et al (2013)). It is concluded that the shock is absorbed rapidly and the return to a steady state occurs around the last hour of continuous quotation (from $1 \mathrm{pm}$ ). Also, Fig.1 illustrates the response of the endogenous variables to the impact of the specified variable as well as the return to equilibrium time that a positive shock to transaction frequency initially decreases spreads and later increases marginally and stabilizes in the long-run.

The stability graphs show that PVAR satisfies the stability conditions (Fig.2). The VAR model is stable if all the companion matrices are strictly less one (Abrigo and Love, 2015). Thus, the VAR model is stable if all the eigenvalues lie in the unit circle. From the roots of the companion matrix, the TPI, effective spread, volatility and size, eigenvalues lie in the unit circle which suggests that the PVAR models are stable and the results are good for forecasting and market recommendation. 


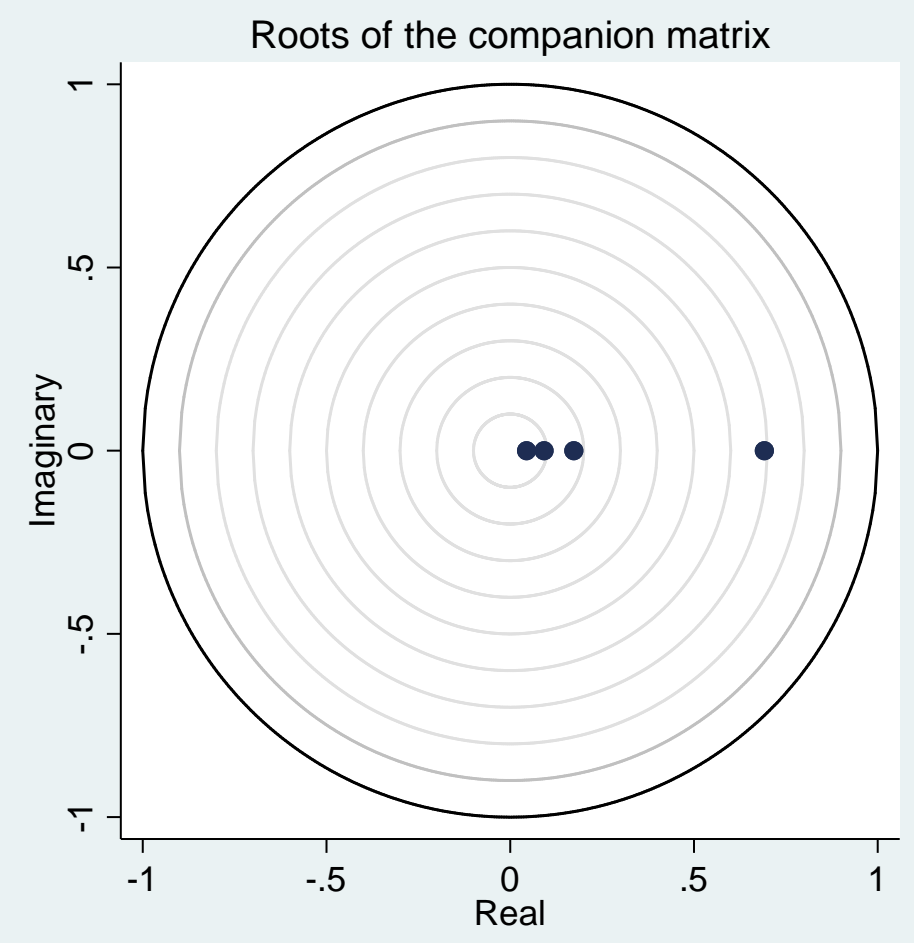

Figure 2. Stability graph

\section{Conclusions}

The adoption of a sophisticated trading system on the Tunis Stock Exchange and the importance of transaction intensity in defining market liquidity, was our motivation throughout our work. We seek to enrich the literature through an application of the Jarnecic and Snape (2014) model adopted to our context. Indeed, the choice of the Abrigo and Love (2015) method of the Panel Var on intra-day data relating to orders submitted to the central book of the Tunis Stock Exchange, allowed us to define certain measures of variables of the model of Jarnecic and Snape (2014). Our objective is to determine the variables influencing the liquidity of the market on one hand, and the causal links as well as the responses to the shock of the variable defining the trading strategies, the liquidity of the market, the volatility and the capitalization of securities on the other hand.

On a sample of 40 companies belonging to the Tunindex Index for the period from 01 April to 30 June 2014, the results of the estimates through the Panel Var, allow us, to detect the variables affecting the liquidity of the market and in this case we find that the transaction frequency has a significant impact on the liquidity of the market. This is consistent with the theoretical and empirical literature highlighting the importance of transaction frequency in improving market quality such as Hasbrouck and Saar (2013). This observation is further confirmed by the impulse response functions to the impact of the various variables. Significant shocks in our case relate primarily to range responses, trader position and stock volatility. Although the transaction frequency remains limited, which has led us to widen the quotation interval to 45 minutes to better detect the ordering percentages, our results allow us to detect the importance of strategies adopted by traders in improving the quality of our stock market. We find results that are explained on the one hand by the inventory flow and on the other by the flow of information asymmetry. An analysis on the broader implications of the relationship between order transactions intensity and market liquidity concludes that HFT contributes positively to the liquidity make-take cycle, and their activity is associated with a reduction in bid-ask spreads. An examination of the effect of transaction frequency on transaction costs for long-term investors and factors such as the contribution to quoted depth and the difficulty of trading for participants is left to future research. 


\section{References}

Abrigo Michael R. M., \& Love Inessa. (2016). Estimation of Panel Vector Autoregression in Stata. The Stata Journal: Promoting Communication on Statistics and Stata, 16(3), 778-804. https://doi.org/10.1177\%2F1536867X1601600314

Ahn, H. J., Bae, K., \& Chan, K. (2001). Limit orders, depth and volatility: Evidence from the Stock Exchange of Hong Kong. Journal of Finance, 56, 769-790. https://doi.org/10.1111/0022-1082.00345

Andrews, D. W. K., \& B. Lu. (2001). Consistent model and moment selection procedures for GMM estimation with application to dynamic panel data models. Journal of Econometrics, 101(1), 123-164. https://doi.org/10.1016/S0304-4076(00)00077-4

Biais, B., Hillion, P., \& Spatt, C. (1995). An Empirical Analysis of The Limit Order Book and the Order Flow in the Paris Bourse. The Journal of Finance, 50(5), 1655-1689. https://doi.org/10.2307/2329330

Coppejans, M., I. Domowitz, \& A. Madhavan. (2004). Resiliency in an automated auction. Working paper, ITG.

Danielsson, J., \& R. Payne. (2002). Liquidity determination in an order driven market. Working paper, London School of Economics. https://doi.org/10.1080/1351847X.2011.601654

Degryse, H., De Jong, F., \& Kervel. V. (2005). The Impact Of Dark Trading and Visible Fragmentation on Market Quality. TILEC Discussion Paper n²011-026, SSRN Library. https://doi.org/10.2139/ssrn.1815025

Dong, J., A., Kempf, \& P. K. Yadav. (2007). Resiliency, the neglected dimension of market liquidity: Empirical evidence from the New York Stock Exchange. Working paper, SSRN: http://ssrn.com/abstract=967262. https://doi.org/10.2139/ssrn.967262

Foucault, T., Roell \& Sandas, P. (2007). Market making with costly monitoring: an analysis of the SOES controversy. Review of Financial Studies, 16, 345-384. https://doi.org/10.1093/rfs/hhg005

Foucault, Thierry, \& Albert J. Menkveld. (2008). Competition for Order Flow and Smart Order Routing Systems. The Journal of Finance, 63, 119-58. https://doi.org/10.1111/j.1540-6261.2008.01312.x

Griffiths, M. D., B. F. Smith, A. D. S. Turnbull, \& R. W. White. (2000). The costs and determinants of order aggressiveness. Journal of Financial Economics, 56(1), 65-88. https://doi.org/10.1016/S0304-405X(99)00059-8

Handa, P., R. Schwartz, \& A. Tiwari. (2003). Quote setting and price formation in an order driven market. Journal of Financial Markets, 6, 461-489. https://doi.org/10.1016/S1386-4181(02)00041-1

Harris, Lawrence. (1994). Order exposure and parasitic traders. Working Paper. University of Southern California.

Hasbrouck, J., \& Saar, G. (2009). Technology and liquidity provision the blurring of traditional definitions. Journal of Financial Markets, 12, 143-172. https://doi.org/10.1016/j.finmar.2008.06.002

Hasbrouck, J., \& Saar, G. (2013). Low-Latency Trading. Journal of Financial Markets, 16, 646-679. https://doi.org/10.1016/j.finmar.2013.05.003

Hasbrouck, J., \& Saar, G. (2013). Low-Latency Trading. Journal of Financial Markets, 16, $646-679$. https://doi.org/10.1016/j.finmar.2013.05.003

Hautsch, N., \& R. Huang. (2012). The market impact of a limit order. Journal of Economic Dynamics and Control, 36(4), 501-522. https://doi.org/10.1016/j.jedc.2011.09.012

Hendershott, T., \& R. Riordan. (2013). Algorithmic trading and the market for liquidity, Journal of Financial and Quantitative Analysis, 48, 1001-1024. https://doi.org/10.1017/S0022109013000471

Hendershott, Terrence J., \& Moulton, Pamela C. (2011). Automation, Speed, and Stock Market Quality: The NYSE's Hybrid. Available at $\quad$ SSRN: https://ssrn.com/abstract=1159773. https://doi.org/10.1016/j.finmar.2011.02.003

Hmaied, D. M., A. Grar, \& O. B. Sioud. (2006). Dynamics of market liquidity of Tunisian stocks: An analysis of market resiliency. Electronic Markets, 16(2), 140-153. https://doi.org/10.1080/10196780600643977

Hollifield. B, R. Miller, P. Sandås, \& J. Slive. (2006). Estimating the gains from trade in limit-order markets. Journal of Finance, 61(6), 2753-2804. https://doi.org/10.1111/j.1540-6261.2006.01004.x

Holtz-Eakin, D., W. Newey, \& H. S. Rosen. (1988). Estimating vector autoregressions with panel data. Econometrica, 56(6), 1371-1395. https://doi.org/10.2307/1913103 
Holtz-Eakin, Douglas and Newey, Whitney K., \& Rosen, Harvey S. (1988). Implementing Causality Tests with Panel Data, with an Example from Local public Finance. NBER Working Paper No. t0048. https://doi.org/10.3386/t0048

Jarnecic. E., \& Snape, M. (2014). The Provision of Liquidity by High frequency Participants. The Financial Review, 49(2014), 371-394. https://doi.org/10.1111/fire.12040

Kelejian, Harry H., \& Purba Mukerji. (2016). Does high frequency algorithmic trading matter for non-AT investors? Research in International Business and Finance, 37, 78-92. https://doi.org/10.1016/j.ribaf.2015.10.014

Large, J. (2007). Measuring the resiliency of an electronic limit order book. Journal of Financial Markets, 10(1), 1-25. https://doi.org/10.1016/j.finmar.2006.09.001

Love, I., \& Ziccino, L. (2006). Financial development and dynamic investment behavior: Evidence from panel VAR. The Quarterly Review of Economics and Finance, 46(2), 190-210. https://doi.org/10.1016/j.qref.2005.11.007

Ranaldo, A. (2004). Order aggressiveness in limit order book markets. Journal of Financial Markets, 7, 53-74. https://doi.org/10.1016/S1386-4181(02)00069-1

Roll, R. (1984). A Simple Measure of the Bid-Ask Spread in an Efficient Market. Journal of Finance, 39, 1127-1140. https://doi.org/10.1111/j.1540-6261.1984.tb03897.x

Sims, C. A. (1980). Macroeconomics and reality. Econometrica, 48(1), 1-48. https://doi.org/10.2307/1912017

Strange and Kaserer. (2011). Measuring Market Liquidity Risk - Which Model Works Best? CEFS Working Paper Series 2009 No. 1. https://doi.org/10.2139/ssrn.1328480

Zhang, Frank. (2010). High-Frequency Trading, Stock Volatility, and Price Discovery. Available online: http://ssrn.com/abstract=1691679. https://doi.org/10.2139/ssrn.1691679

\section{Copyrights}

Copyright for this article is retained by the author(s), with first publication rights granted to the journal.

This is an open-access article distributed under the terms and conditions of the Creative Commons Attribution license (http://creativecommons.org/licenses/by/4.0/). 